\title{
Licenciaturas em Educação do Campo da área de Ciências da Natureza: análise da produção em periódicos nacionais
}

\author{
Antonio Marcos Teixeira Dalmolin ${ }^{1}$, Rosane Nunes Garcia ${ }^{2}$ \\ ${ }^{1}$ Universidade Federal do Rio Grande do Sul - UFRGS. Departamento de Ensino e Currículo da Faculdade de Educação. \\ Avenida Paulo Gama, 110, Farroupilha, Porto Alegre - RS. Brasil. ${ }^{2}$ Universidade Federal do Rio Grande do Sul - UFRGS. \\ Departamento de Ciências Exatas e da Natureza do Colégio de Aplicação; Programa de Pós-Graduação em Educação em \\ Ciências: Química da Vida e Saúde. \\ Autor para correspondência/Author for correspondence: antoniodalmolin@gmail.com
}

RESUMO. O presente artigo investiga como as Licenciaturas em Educação do Campo articulam-se com a área das Ciências da Natureza, a partir das produções socializadas em periódicos nacionais, da área de Ensino da CAPES, entre os anos de 2013 a 2017, com classificação Qualis A1, A2 e B1. As fontes da pesquisa foram 14 artigos, dentre os 4189 artigos publicados em 25 periódicos. A pesquisa é qualitativa, do tipo bibliográfica, e a técnica de análise foi a Análise Textual Discursiva. Os resultados foram sintetizados em três categorias interrelacionadas, denominadas: a) Currículos e Culturas na Educação do/no Campo em Ciências da Natureza; b) Formação Docente do/no Campo em Ciências da Natureza; c) Ciência Tecnologia - Sociedade e Implicações Socioambientais. Destacamos a presença de três elementos centrais, inseparáveis, que são: as populações do campo, os contextos e as intencionalidades. Assim, educadores, educadoras e estudantes, que vivem e trabalham nos diferentes contextos do campo, que vivenciam e problematizam as intencionalidades na Educação, nas Ciências da Natureza e na sociedade, encontram na Educação do Campo um lugar de debate sobre as contradições vividas e de construção de outros caminhos possíveis em termos de sociedade.

Palavras-chave: Educação do Campo, Ciências da Natureza, Licenciatura, Produção Bibliográfica, Formação de Professores.

\begin{tabular}{l|l|l|l|l|} 
RBEC & Tocantinópolis/Brasil & v. 5 & e6455 & $10.20873 /$ uft.rbec.e6455 \\
\hline
\end{tabular}

$2020 \quad$ ISSN: $2525-4863$




\title{
Licentiate courses in Rural Education of the Area of Natural Sciences: analysis of the production in national journals
}

\begin{abstract}
This paper investigates how licentiate courses in Rural Education articulate with the area of the Sciences of Nature, from the productions socialized in Brazil, from the Teaching area of CAPES, between the years of 2013 to 2017, with classification A1, A2 and B1. The sources of the research were 14 articles, among 4189 articles published in 25 journals. The research is qualitative, of the bibliographic type, and the technique of analysis was the Textual Discourse Analysis. The results were synthesized in three categories interrelated: a) Curriculums and Cultures in Rural Education in Natural Sciences; b) Teacher Training in Rural Education in Natural Sciences; c) Science - Technology - Society and Social and Environmental Implications. We highlight the presence of three central, inseparable elements: the rural populations, contexts and intentionalities. So, teachers and students, who live and work in different rural contexts, too experience and problematize the intentionalities in Education, the Natural Sciences and society. They find in Rural Education a place of discussion about the lived contradictions and the construction of other possible ways of society.
\end{abstract}

Keywords: Rural Education, Natural Sciences, licentiate course, Bibliographic Production, Teacher Education. 


\section{Licenciaturas en Educación Rural del área de Ciencias de la Naturaleza: análisis de la producción en periódicos nacionales}

RESUMEN. Este artículo investiga cómo las Licenciaturas en Educación Rural se articulan con el área de las Ciencias de la Naturaleza, a partir de las producciones socializadas en periódicos nacionales, del área de Enseñanza de la CAPES, entre los años de 2013 a 2017, con clasificación A1, A2 y B1. Las fuentes de la investigación fueron 14 artículos, entre los 4189 artículos publicados en 25 periódicos. La investigación es cualitativa, del tipo bibliográfica, y la técnica de análisis fue la Análisis Textual Discursiva. Los resultados se sintetizaron en tres categorías interrelacionadas, llamada: a) Currículos y Culturas en la Educación Rural en Ciencias de la Naturaleza; b) Formación Docente del / en el Campo en Ciencias de la Naturaleza; c) Ciencia - Tecnología - Sociedad e Implicaciones Socioambientales. Resaltamos la presencia de tres elementos centrales, inseparables, que son: las poblaciones del campo, los contextos y las intencionalidades. Así, profesores y estudiantes viven $\mathrm{y}$ trabajan en diferentes regiones rurales, que experimentan y problematizan las intencionalidades en Educación, Ciencias de la Naturaleza y sociedad, encuentran en la Educación Rural un lugar de debate acerca de las contradicciones vividas y de la construcción de otras formas posibles de sociedad.

Palabras clave: Educación Rural, Ciencias de la Naturaleza, Licenciatura, Producción Bibliográfica, Formación del Profesorado. 


\section{Introdução}

Em suas origens históricas, a Educação do Campo tem vinculação com movimentos sociais, principalmente na luta pela terra, pela reforma agrária e com o compromisso de produção de alimentos em equilíbrio com o ambiente. A partir do final dos anos de 1980, no Brasil, com a abertura ao processo de redemocratização e com a promulgação da Constituição Federal de 1988, as vozes dos movimentos ligados ao campo se amplificaram, não somente pelo clamor à terra, mas também por políticas públicas que tratassem do enfrentamento ao acentuado êxodo rural ocorrido no final do século $\mathrm{XX}$, bem como a construção de uma educação de qualidade e contextualizada para os sujeitos do campo.

$\mathrm{Na}$ esteira de aprofundar o debate sobre a valorização do campo como espaço de vida, trabalho e cultura, foi organizada em julho de 1998, em Luziânia-GO, a "Primeira Conferência Nacional: por uma Educação Básica do Campo”. Segundo Fernandes, Cerioli e Caldart (2004, p. 22), este evento objetivou discutir o espaço do campo e da Educação do Campo na agenda política brasileira. Essa conferência foi considerada um dos marcos iniciais da Articulação Nacional que se constituiu em prol da Educação do Campo, com intensa participação de movimentos sociais, e que em 2018 comemorou 20 anos de luta.

Como desdobramento de tal articulação, aliado com a disponibilidade e abertura ao diálogo do Ministério da Educação (MEC), nos anos 2000, nascem as primeiras Licenciaturas em Educação do Campo (LEDOC).

De forma resumida, vale ressaltar
que, como política pública do MEC,
essa proposta de formação docente
teve início em 2007 com quatro
experiências-piloto desenvolvidas
pelas Universidade Federal de Minas
Gerais (UFMG), Universidade de
Brasília (UnB), Universidade Federal
de Sergipe (UFS) e Universidade
Federal da Bahia (UFBA), mediante
a criação do Programa de Apoio à
Formação Superior em Licenciatura
em Educação do Campo
(PROCAMPO). (Molina, 2017a, p.
03).

$\mathrm{Na}$ sequência, via edital, o MEC ampliou o número de cursos em 2008 e 2009, conforme descreve Molina (2017a, p. 03). No entanto, foi em 2012 que houve um incremento significativo nesta política pública, com a criação de mais de 40 cursos através do Edital de Seleção $N^{\circ}$ 02/2012 SESU/SETEC/SECADI/MEC, bem como a criação de 600 novas vagas docentes do Magistério Superior e mais de 120 servidores técnicos administrativos em educação nas Universidades Federais. O referido edital cita a razão de 15 vagas 
docentes e 03 técnicos administrativos para cada curso aprovado. Do total de cursos de LEDOC, mais de 50 nos dias atuais, a maioria é parte da Rede Federal, Universidades e Institutos Federais de Educação, Ciência e Tecnologia, e uma menor fração em instituições públicas estaduais.

As LEDOC estão organizadas em áreas do conhecimento que, segundo o referido Edital, são: Linguagens e Códigos; Ciências Humanas e Sociais; Ciências da Natureza, Matemática; Ciências Agrárias e combinações delas, com prioridade para a formação de professores nas áreas de Matemática e de Ciências da Natureza em função da carência de docentes com tais formações em atuação na Educação Básica do campo. Essa proposição resultou na constituição de 34 cursos, na Rede Federal, de Licenciatura em Educação do Campo nas áreas de Ciências da Natureza ou Ciências da Vida e Natureza e combinações com Matemática ou com Ciências Agrárias. Os referidos cursos estão distribuídos nas cinco regiões do país, sendo 10 na região Sul, 05 na Sudeste, 04 na Centro-Oeste, 09 na Nordeste e 06 na Norte. Os números supracitados foram compilados a partir de Molina (2015, p. 21-22) e da Portaria $n^{\circ}$ 072 (2012), bem como a pesquisa nos endereços eletrônicos das instituições que ofertam as LEDOC.

A matriz teórico-filosófica da Educação do Campo tem no educador Paulo Freire uma das referências, tanto em função de sua contribuição no debate sobre Educação Popular, quanto pela contribuição da organização curricular de parte das LEDOC, estruturadas a partir de temas geradores, ou não, segundo a concepção do autor em Freire (2019, p. 107-166). Em função dessa contribuição de Paulo Freire na Educação do campo e também de trabalhos que, desde a década de 1980, buscam balizar a Educação em Ciências em pressupostos freireanos justificamos a potencialidade da articulação do autor com a Educação do Campo na área de conhecimento das Ciências da Natureza.

As contribuições do Pensamento Latino-Americano sobre Ciência, Tecnologia e Sociedade (PLACTS) também são referências importantes, que apresentam produtivas interfaces e articulações, com trabalhos balizados pelas contribuições do educador Paulo Freire na construção de projetos nacionais de desenvolvimento voltados ao enfrentamento das problemáticas sociais/locais, bem como a participação do conjunto da população nas decisões sobre temas que envolvem ciência e tecnologia. 
O cenário aqui apresentado debate sobre uma política pública que criou mais de 30 cursos de Licenciatura em Educação do Campo na área de Ciências da Natureza, nesta década, e que a maioria deles completou um ciclo com a diplomação da primeira turma até o ano de 2018, além de vivenciarem os processos de reconhecimento do curso junto ao MEC. Destacamos, portanto, o contexto em que a pesquisa em Educação em Ciências, alinhada à Educação do Campo, ganha um significativo incremento de recursos humanos pela contribuição dos professores concursados para atuar nestes cursos e, passados os anos iniciais da docência, sensibilizados com a realidade, esses docentes teriam possibilidades de produzir e socializar suas vivências e experiências, entre outros espaços, em periódicos nacionais.

A partir desses aspectos, justificamos e delimitamos esta investigação, da qual emerge o presente problema de pesquisa: como as Licenciaturas em Educação do Campo articulam-se com a área das Ciências da Natureza, a partir das produções socializadas em periódicos nacionais, da área de Ensino?

Como objetivos, a presente pesquisa pretende: a) investigar e caracterizar a produção na área de Educação em Ciências, no contexto das Licenciaturas em
Educação do Campo, socializada em periódicos nacionais da área de Ensino da CAPES entre os anos de 2013 a 2017, com classificação Qualis A1, A2 e B1; b) construir e aprofundar reflexões em torno de aspectos teórico-metodológicos da Articulação Freire-PLACTS, no contexto da Educação do Campo.

\section{Encaminhamentos metodológicos}

Teórico-

Em termos de referenciais teóricos essa pesquisa se apoia em uma tríade composta de autores da área de Educação do Campo, trabalhos balizados por contribuições do educador brasileiro Paulo Freire e referenciais ligados à corrente latino-americana do Movimento CiênciaTecnologia-Sociedade (CTS), denominada PLACTS. Destacamos também as contribuições de Molina (2014, 2017b) pela sistematização de experiências e reflexões produzidas sobre o processo de formação docente em Educação do Campo para o Trabalho Interdisciplinar em Ciências Naturais e Matemática. Sublinhamos ainda o trabalho de Arroyo, Caldart e Molina (2004, p. 12-13) que postulam como o grande desafio da Educação do Campo "entender os processos educativos na diversidade de dimensões que os constituem como processos sociais, políticos e culturais, 
formadores do ser humano e da própria sociedade".

Outro elemento a ser considerado é a superação de algumas questões fundamentais, apontadas pelos autores citados, que acompanham historicamente a Educação do Campo, quais sejam: o esquecimento e desinteresse do Estado para com o campo; o clamor da terra por aqueles que lutam contra as desigualdades construídas pelos latifúndios de terra; a negação dos direitos aos que têm direito, como a negligência à educação para os sujeitos do campo; e a construção de um novo olhar para o campo, de superação da concepção hegemônica de que o campo é sinônimo de atraso, com a proposição de um novo modelo de campo, sustentável e produtivo.

Tais questões fundamentais figuram na pauta dos movimentos sociais do campo com objetivo de construir políticas públicas que valorizem a cultura, a vida e o trabalho no campo, sem a transformação para uma vida urbana. Esse movimento de transformar o meio rural em cidade é análogo à crítica de Freire (2006, p. 45) sobre a invasão cultural, na qual, por força da mídia, do consumismo exacerbado e até mesmo de práticas equivocadas de extensão universitária, são construídas visões de mundo urbanas que se superpõem ao contexto local, rural.
O referido educador brasileiro contribuiu para a constituição do campo de conhecimento da Educação do Campo, pela sua práxis educacional no debate da Educação Popular, desde o século passado, e mais recentemente, por inspirar currículos em cursos de Licenciatura em Educação do Campo, como exemplo o Projeto Pedagógico da LEDOC da UFRGS (2013), estruturado a partir de temas denominados geradores, com inspiração em Freire (2019), "Pedagogia do Oprimido", que propõe outra organização curricular a partir de temas investigados na realidade dos estudantes.

A abordagem de temas na Educação em Ciências também está presente em autores como Delizoicov, Angotti e Pernambuco (2002), que inspirados em Snyders (1988) e Freire (2019), entendem a abordagem temática como uma:

\begin{abstract}
Perspectiva curricular cuja lógica de organização é estruturada com base em temas, com os quais são selecionados os conteúdos de ensino das disciplinas. Nessa abordagem, a conceituação científica da programação é subordinada ao tema. (Delizoicov, Angotti \& Pernambuco, 2002, p. 189).
\end{abstract}

Cabe destaque às contribuições de (Auler, 2002, 2018) que buscaram balizar a Educação em Ciências em pressupostos resultantes da articulação entre referenciais ligados a Paulo Freire e ao Movimento 
CTS e PLACTS, em função de sua participação na matriz teórico-filosófica da Educação do Campo.

Os trabalhos referenciados por Freire apresentam produtivas interfaces $\mathrm{e}$ articulações, com trabalhos balizados pelo PLACTS, na construção de ações locais de desenvolvimento, nas críticas ao capitalismo e à sociedade classista. Representante do PLACTS, Dagnino (2010, p. 284), ao fazer uma análise do Ensino Superior, afirma que a universidade pública na América Latina é disfuncional tanto para a sociedade, quanto para o contexto mais amplo. Ele também critica o ensino repetitivo, a pesquisa autorreferenciada, vinculada a agendas construídas no hemisfério norte e o caráter ofertista da extensão universitária.

O PLACTS defende o redesenhar da Ciência e Tecnologia (CT) vigentes. Embora não haja linearidade e dependência exclusiva do desenvolvimento social em função do desenvolvimento da CT, há uma forte influência vinculada à dinâmica social contemporânea, marcada pela Ciência-Tecnologia. Tal redesenhar da CT significa tomar como ponto de partida os conhecimentos, histórico

e
epistemologicamente, produzidos pelos seres humanos. A construção de modelos alternativos (ao vigente) do desenvolvimento da CT está atrelada ao modelo de sociedade que se pretende construir, mais democrática e partícipe das decisões sociais.

Assim, o PLACTS se aproxima da Educação do Campo no compartilhamento de algumas raízes teóricas ligadas ao materialismo histórico e dialético e pelas potenciais construções em torno do conceito de tecnologias sociais, que são as tecnologias construídas no âmbito dos empreendimentos cooperativos, solidários e auto gestionários.

Em termos metodológicos a presente pesquisa é classificada, quanto à abordagem, como qualitativa, que segundo Minayo (2002, p. 16) preocupa-se com um nível de realidade não quantificável, ou seja, trabalha com "significados, motivos, aspirações, crenças, valores e atitudes, o que corresponde um espaço mais profundo das relações, dos processos e dos fenômenos". Para Moraes e Galiazzi (2016, p. 33), as pesquisas qualitativas pretendem aprofundar a compreensão dos fenômenos que investigam sem a pretensão de "testar hipóteses para comprová-las ou refutá-las ao final da pesquisa; a intenção é a compreensão".

Quanto aos procedimentos, a pesquisa é do tipo bibliográfica, segundo Gonsalves (2001, p. 34), caracterizada pela “identificação e análise dos dados escritos em livros, artigos de revistas, entre outros. 
Sua finalidade é colocar o pesquisador em contato com o que já se produziu a respeito do seu tema de pesquisa". No que concerne à definição de documentos, nesta investigação, representados por artigos de periódicos, Alves-Mazzotti e Gewandznajder (1998, p. 169) entendem documento como "qualquer registro escrito que possa ser usado como fonte de informação".

No que se refere à técnica de análise dos resultados, foi escolhida a Análise Textual Discursiva (ATD), segundo Moraes e Galiazzi (2016, p. 33). Para os referidos autores, a ATD é adequada a pesquisas qualitativas, pois estas têm por objetivo a compreensão dos fenômenos em profundidade.

A ATD, segundo Moraes e Galiazzi (2016, p. 34), consiste em um processo auto-organizado de construção de compreensões, composto de uma sequência recursiva de três componentes, que passam pela desconstrução da ordem do corpus da pesquisa (unitarização), pela reordenação dos produtos da desconstrução desses textos (categorização) e pela criação de uma nova ordem, novos textos, metatextos, relacionados com os textos originais (comunicação).

O corpus da pesquisa foi composto por artigos de 25 periódicos brasileiros da área de Ensino, avaliados pela
Coordenação de Aperfeiçoamento de Pessoal de Nível Superior (CAPES), com classificação Qualis A1, A2 e B1, no período de 2013 a 2017. Foram analisados artigos de periódicos de instituições públicas e privadas de todas as regiões do Brasil, de modo a tornar a amostra representativa. Os periódicos foram escolhidos a partir de busca na Plataforma Sucupira da CAPES. Conforme os critérios propostos para a seleção do corpus, apenas os estados do Acre, Amapá, Roraima, Ceará e Piauí não possuem periódicos na área de Ensino, com os Qualis propostos.

A justificativa para a escolha dos artigos publicados no período decorre da oferta de cursos de Licenciatura em Educação do Campo a partir do Edital de Seleção $\quad n^{\circ} \quad 02 / 2012$ SESU/SETEC/SECADI/MEC, que criou e financiou mais de 30 cursos de Licenciatura em Educação do Campo na área de Ciências da Natureza. Consequentemente, o impacto de publicações resultantes de tal política ocorreria nos anos seguintes.

A seleção do corpus da pesquisa foi organizada em 3 etapas:

$1^{\text {a }}$ Etapa: foram selecionados artigos auto identificados no título e/ou resumo e/ou palavras-chave com os seguintes termos: Ensino de/das/nas Ciências; Educação em/nas Ciências; Educação em 
Ciência; Ciência e Tecnologia; CiênciaTecnologia; Ciências da Natureza e Ciências Naturais. Foram analisadas publicações de 05 periódicos de cada região do país, de 2013 a 2017.

Os 25 periódicos consultados foram: (2175-6236) Educação e Realidade, (19840411) Educar em Revista, (1982-5153) Alexandria Revista de Educação em Ciência e Tecnologia, (1982-873x) Revista Brasileira de Ensino de Ciência e Tecnologia, (2237-4450) Ensino de Ciências e Tecnologia em Revista, (1980850x) Ciência \& Educação (online), (19832117) Ensaio: Pesquisa em Educação em Ciências (online), (1809-449x) Revista Brasileira de Educação, (1806-5104) Revista Brasileira de Pesquisa em Educação em Ciências, (1982-7660) Revista de Educação Popular, (2176-6681) Revista Brasileira de Estudos Pedagógicos RBEP-INEP, (2177-7691) Interfaces da Educação, (2238-2097) Revista Educação Pública da UFMT, (2237-1648) Educação, Cultura e Sociedade, (1981-8416) Interação (online), (1981-1802) Revista Educação em Questão (online), (01047043) Revista FAEEBA: Educação e Contemporaneidade, (2447-0783) Revista Eletrônica Científica Ensino Interdisciplinar, (2175-6600) Debates em Educação, (1677-6097) Educação e Emancipação, (2317-5125) Amazônia -
Revista de Educação em Ciências e Matemáticas (online), (1984-7505) Areté Revista Amazônica de Ensino de Ciências, (2525-4863) Revista Brasileira de Educação do Campo, (2446-774x) Revista de Estudos e Pesquisas sobre Ensino Tecnológico, e (2359-2087) Educa Revista Multidisciplinar em Educação.

Foram publicados 4189 artigos, de 2013 a 2017, nos 25 periódicos citados. A partir dos parâmetros aplicados nesta etapa, foram selecionados 481 artigos que atendiam ao primeiro critério de seleção. $\mathrm{O}$ número de artigos publicados por ano apresentou pequena variação, sendo 91 em 2013, 87 em 2014, 97 em 2015, 104 em 2016 e 102 em 2017, perfazendo uma média anual de 96 publicações na área de Educação em Ciências, na mostra analisada.

$2^{\text {a }}$ Etapa: Em função do elevado número e da diversidade de temas tratados, foram selecionados do conjunto de 481 trabalhos, os artigos auto identificados no título e/ou resumo e/ou palavras-chave com os seguintes termos: Educação do/no Campo, Educação Rural, escola do/no campo, populações do campo. Deste processo de delimitação do corpus restaram 29 artigos que atenderam ao segundo critério de seleção.

O número de artigos publicados por ano, na área de Educação do Campo e 
Ciências da Natureza, apresentou crescimento no período: 01 em 2013, 04 em 2014, 04 em 2015, 06 em 2016 e 14 em 2017. Realizamos a primeira leitura dos 29 artigos, selecionados nesta etapa, de modo a iniciar o mergulho no material analisado e delimitar o corpus da pesquisa.

Do total referido, 11 trabalhos discutiam temas relacionados às escolas do campo, populações do Campo e conhecimentos/saberes populares e tradicionais no diálogo com as Ciências da Natureza; 01 revisão bibliográfica sobre Educação Indígena; 01 reflexão sobre Educação do Campo no âmbito da Pósgraduação; 01 sobre história e cultura Afro-Brasileira na Licenciatura em Ciências da Natureza e Matemática; 01 sobre o curso de Licenciatura Intercultural Indígena e 14 foram experiências relacionadas aos cursos de Licenciatura em Educação do Campo na área de conhecimento das Ciências da Natureza.

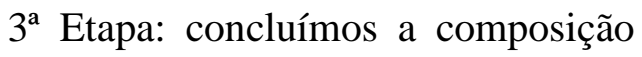
do corpus da pesquisa com os 14 artigos que tratavam sobre as Licenciaturas em Educação do Campo e a área de Ciências da Natureza, sendo eles: Brito e Silva (2015), Fernandes e Stuani (2015), Faleiro e Farias (2016), Cunha e Silva (2016), Formigosa et al. (2017), Crepaldi, Klepka e Pinto (2017), Marques (2017), Mendes e Grilo (2017), Prsybyciem, Santos e Sartori
(2017), Borges, Faria e Brick (2017), Halmenschlager et al. (2017), Fonseca, Duso e Hoffmann (2017), Moradillo, Messeder Neto e Massena (2017), Araújo, Assis e Costa (2017).

\section{Diálogos entre os resultados es referenciais teóricos}

Na primeira etapa da análise, após a delimitação do corpus com uma amostragem de documentos adequada ao problema de pesquisa e objetivos, ocorreu a unitarização. Esta correspondeu ao movimento desconstrução/desmontagem dos textos analisados na pesquisa, pois a construção de uma "nova ordem" passou primeiramente por uma "desordem". A desordem iniciou pela leitura e significação dos 14 artigos de periódicos selecionados, considerando que, segundo Moraes e Galiazzi (2016, p. 35), há multiplicidade de leituras possíveis, "tanto em função das intenções dos autores como dos referenciais teóricos dos leitores e dos campos semânticos em que se inserem".

No processo de unitarização foram mapeados e detalhados os elementos constituintes do texto e selecionados na forma de fragmentos (ou excertos), denominados unidades de análise. Como resultado desta primeira etapa, foi construída uma lista contendo 160 unidades de análise, que entendemos como 

produção em periódicos nacionais...

representativas para as intenções da pesquisa, organizadas por meio de códigos alfanuméricos, por exemplo, a unidade de análise ART05-C refere ao artigo numerado aleatoriamente com o número 05 e a letra $\mathrm{C}$ indica que foi a terceira unidade de análise extraída do artigo em questão.

Finda a unitarização, iniciamos a segunda etapa denominada categorização que consiste no primeiro momento de síntese, organização e comunicação dos novos entendimentos resultantes da análise. As categorias nesta pesquisa tiveram caráter emergente, nascem do mergulho no corpus e foram construídas a partir de elementos de significação próximos, comparação, contraste e diferenciação. As 160 unidades de análise foram organizadas e deram origem a 52 categorias iniciais. Cabe destacar que uma unidade de análise pode contribuir para a formação de uma ou mais categorias iniciais. O agrupamento destas, por sua vez constituiu 06 categorias intermediárias, que, resultaram em 03 categorias finais, em movimentos do particular ao geral. As categorias finais, inter-relacionadas, foram:

a) Currículos e Culturas na Educação do/no Campo em Ciências da Natureza; b) Formação Docente do/no Campo em Ciências da Natureza; c) Ciência Tecnologia - Sociedade e Implicações Socioambientais.

Como síntese do percurso metodológico da pesquisa, por meio da ATD, organizamos a seguinte figura.

Figura 1 - Sistematização do percurso metodológico desenvolvido nesta pesquisa.

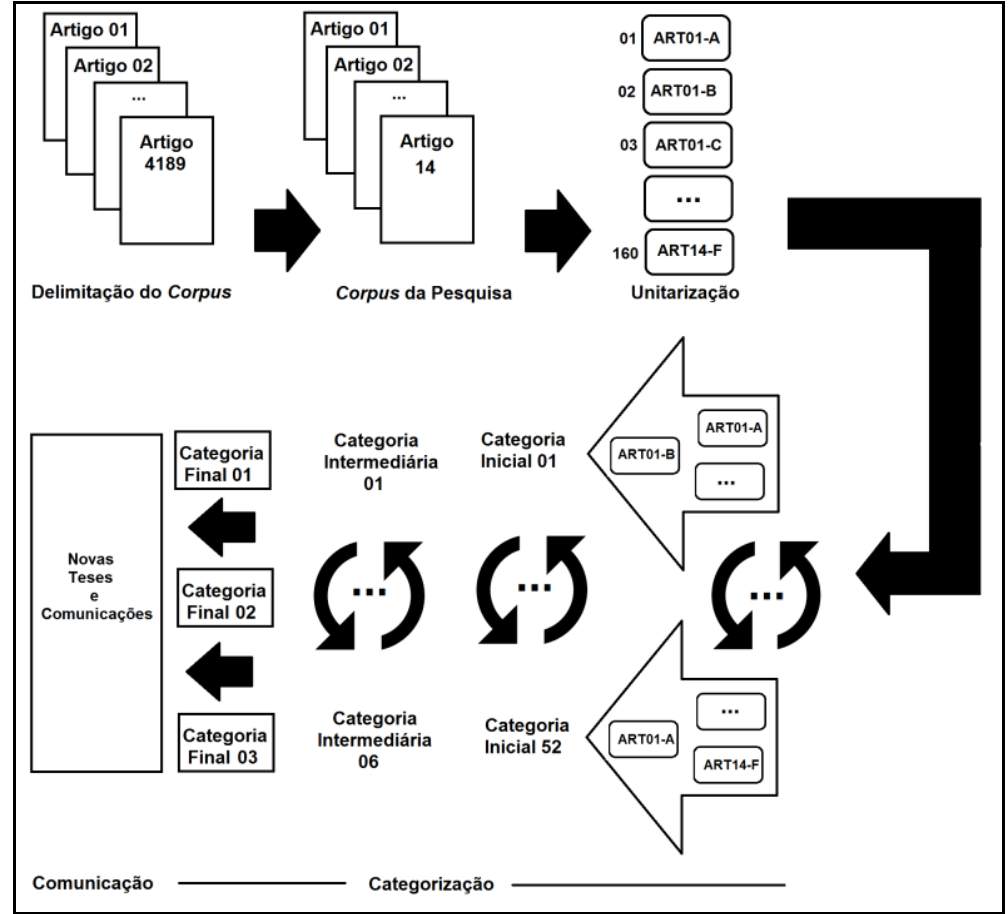

Fonte: Pesquisa dos autores (2019). 
Com a emersão das categorias finais iniciamos a terceira etapa da ATD, a comunicação, na qual, não há intenção de reproduzir os textos originais, mas sim de criar uma nova ordem com a tessitura de novos escritos, que coerentemente dialogam com os textos originais. A comunicação está representada pelas produções oriundas das três categorias, a seguir.

\section{Currículos e culturas na Educação do/no Campo em Ciências da Natureza}

Iniciamos a comunicação do que a literatura analisada apresenta sobre o tema da pesquisa a partir de dois elementos inter-relacionados, que dialeticamente interagem, os currículos e as culturas no contexto da Educação do/no Campo e suas articulações com as Ciências da Natureza.

Desse modo organizamos o texto, inspirado em Freire (2019, p. 133), que ao discutir as relações seres humanos mundo, os temas geradores e o conteúdo programático da educação, tece construtos acerca da interação dialética entre 0 concreto e o abstrato, no qual o concreto é ponto de partida, mas também de chegada no processo educacional (concreto abstrato - concreto).

Nesse contexto, por analogia, nossos movimentos perpassam culturas currículos - culturas, contudo, sem a intenção de reduzir currículos a abstrações ou culturas a concretudes, nem de transformar currículos em culturas e viceversa. Mas sim, de reconhecer as relações dialéticas que se estabelecem entre ambos.

Nosso ponto de partida é a palavra "culturas", com a qual problematizamos sua capacidade de adjetivar seus substantivos, de qualificar seus elementos constituintes, sejam manifestações materiais ou imateriais dos povos a que pertencem. Sublinhamos aqui seu valor substantivo, essencial aos contextos sociais em que se inserem, mas também sua substantividade, enquanto classe gramatical, flexionada em número plural. A opção por utilizar "culturas" se apoia no argumento de que o singular, cultura, não é capaz de representar a diversidade do mundo vivido de modo suficiente, seja no campo, seja na cidade.

Na Educação do Campo também não podemos reduzir o campo à existência de uma única cultura. O Decreto $\mathrm{n}^{\circ} 7352$ (2010), que dispõe sobre a política de Educação do Campo e o Programa Nacional de Educação na Reforma Agrária (PRONERA), define populações e escola do campo como:

I - populações do campo: os agricultores familiares, os extrativistas, os pescadores artesanais, os ribeirinhos, os assentados e acampados da reforma 
agrária, os trabalhadores assalariados rurais, os quilombolas, os caiçaras, os povos da floresta, os caboclos e outros que produzam suas condições materiais de existência a partir do trabalho no meio rural; II - escola do campo: aquela situada em área rural, conforme definida pela Fundação Instituto Brasileiro de Geografia e Estatística - IBGE, ou aquela situada em área urbana, desde que atenda predominantemente a populações do campo. (Decreto $\mathrm{n}^{\mathrm{o}} 7352,2010$ ).

O campo referido no decreto é diverso e plural, no qual as diferentes populações construíram suas diferentes culturas. A diversidade cultural esteve presente nas discussões sobre formação de educadores e educadoras do campo, segundo a unidade de análise ART07-K (Marques, 2017, p. 459), propondo extrapolar os muros da universidade e não se limitar aos estudos teóricos, mas também às vivências práticas dos licenciandos nas comunidades.

As relações sociais, entre outros aspectos, são relações culturais, não monoculturais, o que nos movimenta em defesa da interculturalidade na Educação do Campo e nas Ciências da Natureza. Para ART06-E (Crepaldi, Klepka \& Pinto, 2017, p. 842), “a interculturalidade pressupõe a existência de múltiplas formas de culturas que convivem juntas, o que nos proporciona a diversidade". Logo, a educação intercultural pressupõe relações equitativas, horizontais, dialógicas e de respeito mútuo entre as diferentes culturas que interagem no mundo.

Nesse sentido, emergiu da análise a necessidade de superar a relação vertical existente entre os conhecimentos e saberes escolares, acadêmicos e científicos com os conhecimentos e saberes tradicionais e populares, na qual o primeiro é tratado como superior ao segundo. Para ART06-C (Crepaldi, Klepka \& Pinto, 2017, p. 842), “a formação de professores de ciências para o campo não pode ficar subsumida aos conhecimentos canônicos da ciência escolar sob pena de silenciar e colocar em segundo plano a cultura e as práticas sociais camponesas". Freire defende:

... a necessidade que temos,
educadores e educadoras
progressistas, de jamais subestimar
ou negar os saberes de experiência
feitos, com que os educandos chegam
à escola ou ao centros de educação
informal ... subestimar a sabedoria
que resulta necessariamente da
experiência sociocultural é, ao
mesmo tempo, um erro científico e a
expressão inequívoca da presença de
uma ideologia elitista. (Freire, 1992,
p. 85).

Portanto, Freire entende que negar os saberes de experiência feitos provoca $o$ erro epistemológico, ao não considerar o mundo vivido como ponto de partida do processo educacional, como objeto de problematização. Esse contexto remete ao compromisso de encharcar os currículos com a realidade, com as culturas, de modo 
a que os/as estudantes possam assumir-se como sujeitos participantes, inconclusos, aguçados pela curiosidade epistemológica.

Ao passo em que defendemos a presença dos conhecimentos e saberes tradicionais e populares, também defendemos, com igual importância, a presença dos conhecimentos e saberes escolares, acadêmicos e científicos sistematizados pela humanidade. Para ART13-C (Moradillo, Messeder Neto \& Massena, 2017, p. 994): “... todos os seres humanos, do campo ou da cidade, precisam ser inseridos, de forma intencional, naquilo que a humanidade produziu de mais relevante na atualidade no campo cultural". A referência à cultura inclui as diferentes construções humanas, tais como a Arte, a Filosofia, as Ciências da Natureza e outros campos do conhecimento, além de respeitar as particularidades de comunidades tradicionais.

Em termos curriculares as diferentes realidades vividas, nas interações socioculturais, são objetos de problematização, do professor problematizador, na construção de uma educação libertadora, que contextualizada, nega a concepção bancária da educação. A questão da contextualização do campo nas configurações curriculares foi um ponto de destaque na análise. Segundo ART01-F
(Brito \& Silva, 2015, p. 767), “... a problematização da realidade do campo faz emergir uma temática que conterá situações cotidianas e suas contradições, cujo estudo demandará a compreensão de ciência”, o que corrobora a necessária presença das Ciências da Natureza para a compreensão do mundo vivido.

Para ART03-A (Faleiro \& Farias, 2016, p. 92), os cursos de Licenciatura em Educação do Campo por área do conhecimento estão comprometidos "com um percurso formativo voltado aos saberes e vivências sobre a realidade do campo no âmbito escolar, desconstruindo ideologias urbanocêntricas...”. Assim como o campo, ART08-F (Mendes \& Grilo, 2017, p. 646), entendem que as Ciências da Natureza podem ser estudadas e aprendidas "de maneira integrada, incluída em um contexto social, político, econômico, ético e científico, de maneira não linear".

As questões curriculares foram os assuntos com maior destaque nesta categoria, versando sobre configurações curriculares a partir de temas, tais como: abordagem temática freireana, complexos temáticos e situações de estudo. Em termos de currículo, a unidade de análise ART01-I apresenta sua compreensão de currículo como algo não limitado a:

... uma grade, uma relação de matérias ou um rol de conteúdos predeterminados, métodos e técnicas, 
mas enxergando-o de forma mais ampla, que perpassa todas as ações da escola e na qual se inserem necessariamente a questão da ideologia, do conhecimento e do poder, entendemos que a seleção do conteúdo programático é uma escolha política... (ART01-I). (Brito \& Silva, 2015, p. 768).

Nesse sentido, corroboramos a compreensão de Moreira e Silva (2005, p. 7-8), que entendem o currículo como nada inocente, tampouco "neutro de transmissão desinteressada do conhecimento social. O currículo está implicado em relações de poder, o currículo transmite visões sociais particulares e interessadas, o currículo produz identidades individuais e sociais".

Ainda no espectro do currículo, destacamos, segundo a unidade de análise ART01-J (Brito \& Silva, 2015, p. 769), a contribuição de Freire (2019, p. 133-137) com a concepção dos temas geradores. Estes culminam na construção do programa, mas partem de um processo denominado de investigação temática, composto por cinco etapas: a) “Levantamento preliminar"; b) Análise das situações e escolha das codificações; c) Realização de diálogos descodificadores; d) Redução temática; e) Desenvolvimento do programa em sala de aula.

Percorremos um caminho, nesta categoria, no qual dialeticamente culturas currículos - culturas interagem. Enquanto debatemos as questões culturais, a questão curricular está em interação próxima e vice-versa. As culturas, representativas dos saberes de experiências feitos, são problematizadas no processo educacional como intencionalidade curricular. Enquanto o currículo entra mais intensamente em pauta, as diferentes culturas não se ausentam, pois buscam demarcar sua participação na constituição das pessoas com diálogo horizontal entre os conhecimentos e saberes escolares, acadêmicos e científicos com os conhecimentos e saberes tradicionais e populares.

Logo, enquanto o foco retorna às culturas, a análise ganha contornos avaliativos do processo vivenciado, que contribui para o processo de enculturação do indivíduo nas relações sociais construídas ao longo dos caminhos históricos vividos pelos seres humanos, com intensa colaboração dos currículos que intencionalmente os constituíram como seres humanos sujeitos de suas próprias histórias. E, ao término de um ciclo culturas - currículos - culturas, os processos ciclicamente repetem-se, significam-se e ressignificam-se para dar conta da complexidade, transitoriedade e dinâmica da sociedade contemporânea.

\section{Formação docente do/no Campo em Ciências da Natureza}


Da análise dos artigos que constituíram o corpus da pesquisa emergiu a segunda categoria, Formação Docente do/no Campo em Ciências da Natureza, em relação a qual iniciamos a discussão tomando como ponto de partida a categoria anterior, em função das inter-relações entre currículos, culturas e formação docente.

Para tanto, lançamos mão da etimologia da palavra currículo, que derivada do latim significa caminho, percurso. Sacristán (2013, p. 16) apontou que o conceito de currículo tomou dois sentidos: um relativo à vida profissional das pessoas e suas conquistas ao longo do percurso e outro relativo à constituição da carreira do estudante, no tocante às aprendizagens e as ordem em que deves desenvolver.

No primeiro sentido apresenta-se mais claro o movimento do presente ao passado, na vida estudantil a maioria das situações envolvem movimentos que vão do presente às projeções futuras, à qual caminho vai constituir os sujeitos do processo educacional. Em ambos, o destaque foi a presença de um caminho e as relações que se estabelecem no caminhar.

Logo, organizamos este texto a partir de um percurso formativo, entre muitos possíveis, na formação de professores e professoras de Ciências da Natureza na
Educação do/no Campo. Ao fazer um paralelo entre as questões da formação docente e do currículo na Educação do/no Campo partimos da definição dos perfis de ingressante e egresso. $\mathrm{O}$ perfil do ingressante é o de populações do campo, conforme o Decreto $\mathrm{n}^{\mathrm{o}} 7352$ (2010), nas quais homens e mulheres que vivem $\mathrm{e}$ trabalham no campo possam ter acesso à educação de qualidade em seus espaçostempos de vivência.

Uma educação contextualizada, capaz de problematizar o campo para compreendê-lo, não fica restrita ao âmbito local, tem o local como ponto de partida para entender o global, tal como Freire (1995, p. 25), ao escrever que para ser cidadão do mundo, primeiramente foi cidadão de Recife, sua cidade natal. A contribuição educacional de compreensão da realidade vivida não se encerra em si, mas implica em compreender para intervir, transformar.

Nesse sentido, a Educação do Campo em sua origem e institucionalidade tem estreito vínculo com os movimentos sociais e populares, com as lutas desses movimentos em favor da mudança e transformação da sociedade, principalmente na garantia dos direitos fundamentais, no combate às desigualdades e no respeito às diversidades socioculturais. 
Para ART03-H (Faleiro \& Farias, 2016, p. 104) "o educador do Campo deve ser formado para além da docência, para ser agente de transformação social em defesa dos direitos humanos". Eis um elemento do perfil esperado para os egressos das Licenciaturas em Educação do Campo na área de Ciências da Natureza, a formação de educadores e educadoras do campo, que além de problematizarem as contradições do mundo vivido para sua compreensão à luz das Ciências da Natureza, nos anos finais do Ensino Fundamental, Ensino Médio e Educação de Jovens e Adultos, também são atuantes na transformação social e na defesa dos direitos humanos.

A política que orientou a criação das LEDOC definiu a organização dos cursos em áreas do conhecimento, das quais a Ciências da Natureza faz parte, composta de conhecimentos oriundos das matrizes da Biologia, da Física e da Química. No entanto, tal configuração não tem por objetivo retirar espaço, diminuir a importância ou eliminar as formações disciplinares, mas atender às necessidades contextuais do campo.

Ao ampliar as possibilidades do trabalho coletivo e interdisciplinar, segundo Molina (2017a, p. 9), a organização por áreas do conhecimento objetiva "a organização de novos espaços curriculares que articulam componentes tradicionalmente disciplinares" a partir de problemas reais das localidades. Também destacamos as possibilidades de articulação com espaços educativos não escolares localizados no entorno das escolas do campo, por exemplo, unidades de saúde, colônias de pescadores, organizações cooperativas, associações, organizações comunitárias, entre outras.

Frente à necessidade de superar a fragmentação disciplinar, muitas vezes imposta por ações urbano centristas que negam o campo como espaço-tempo de riqueza cultural, identificamos, segundo ART14-B (Araújo, Assis \& Costa, 2017, p. 927), que “a adoção da interdisciplinaridade atua assim, no sentido de diminuir as fronteiras que cindem a perspectiva social em dicotomias do tipo rural x urbano, campo-cidade".

Um dos pontos centrais da discussão sobre interdisciplinaridade na Educação do Campo é relatado por ART10-A (Borges, Faria \& Brick, 2017, p. 969), segundo o qual, é um "desafio constante de atuar por área de conhecimento, realizando movimentos interdisciplinares, de um modo que não fez parte de nossa formação acadêmica disciplinar". Tal desafio constitui uma limitação na formação disciplinar em Biologia, Física e Química, que pouco oferece aos licenciandos, em 

produção em periódicos nacionais...

termos de créditos obrigatórios, construções teórico-práticas interdisciplinares na Educação em Ciências.

Nesse sentido há consenso em relação à importância da interdisciplinaridade na Educação do Campo e nas Ciências da Natureza, haja vista que a dinâmica social contemporânea é marcada pela Ciência-Tecnologia. No entanto, em nenhuma das 25 unidades de análise que contribuíram para a formação da categoria inicial "Interdisciplinaridade", apresenta uma discussão conceitual e epistemológica sobre o tema.

Em termos do exposto, concordamos com Japiassu (1976, p. 74), que a “interdisciplinaridade se caracteriza pela intensidade das trocas entre os especialistas e pelo grau de integração real das disciplinas, no interior de um projeto específico de pesquisa". Logo, a partir das contribuições de Freire (2019) com a concepção dos temas geradores e a relação dos seres humanos, históricos, entre si e com o mundo vivido, nos afastamos da ideia de interdisciplinaridade como algo intrínseco dos sujeitos e nos aproximamos da compreensão de sua relação com os objetos de estudo, com os temas e problemas reais a serem compreendidos no mundo vivido.
A referida concepção dos temas geradores não figura meramente como uma metodologia, mas como algo que atua sobre o currículo, que o modifica, que o significa e ressignifica no sentido de apropriação da realidade vivida, e esta, possui contornos que não se limitam ao delimitado pelas disciplinas em seus campos de conhecimento e nos conduzem à interdisciplinaridade, em razão das características da dinâmica social contemporânea, não abarcáveis por uma única disciplina ou por várias isoladas em si mesmas.

Outro elemento que emergiu da análise foi a discussão sobre alternância de espaços-tempos de formação, tempos universidade e tempos comunidade, na organização curricular das LEDOC. Ambos os espaços-tempos interagem dialeticamente, pois o trabalho de um está constantemente ligado ao do outro. Nos tempos universidade ou tempos escola, o/a estudante vivencia as aulas na universidade, mas em diálogo com o tempo comunidade. Nos tempos comunidade são desenvolvidas atividades que foram encaminhadas e serão debatidas e socializadas nos tempos universidade.

As unidades de análise, principalmente ART01-L (Brito \& Silva, 2015, p. 770) e ART09-C (Prsybyciem, Santos \& Sartori, 2017, p. 946), discutiram 
o tema e confirmam o valor da alternância como um dos pilares da Educação do Campo, por ser um elemento de interação do currículo com as vivências, por figurar como meio de articulação entre os conhecimentos e saberes escolares, acadêmicos e científicos com os conhecimentos e saberes tradicionais e populares, em seu mover-se dialético entre universidade-comunidade. Outro fator de destaque é a flexibilidade no calendário letivo permitida pela alternância de modo a respeitar os espaços-tempos de vida e trabalho no campo, seja do plantio, da colheita, da pesca, dos rituais, das lutas camponesas etc.

Por fim, concluímos o percurso nesta categoria com a contribuição de ART09-A
(Prsybyciem, Santos \& Sartori, 2017, p. 944), que entendemos reportar aos egressos possíveis saberes docentes do educador e educadora do campo. Segundo a referida unidade de análise, a "Educação do Campo sempre expressou a necessidade de formar professores capazes de compreender as contradições culturais, ideológicas, sociais, políticas, éticas e econômicas enfrentadas pelos sujeitos que vivem do e no campo". Concluo com a figura 2 que esboça a síntese do diálogo entre formação docente e currículo, que perpassa vários temas, não se encerra na colação de grau e segue com a formação continuada dos egressos.

Figura 2 - Síntese sobre a Formação Docente do/no Campo em Ciências da Natureza.

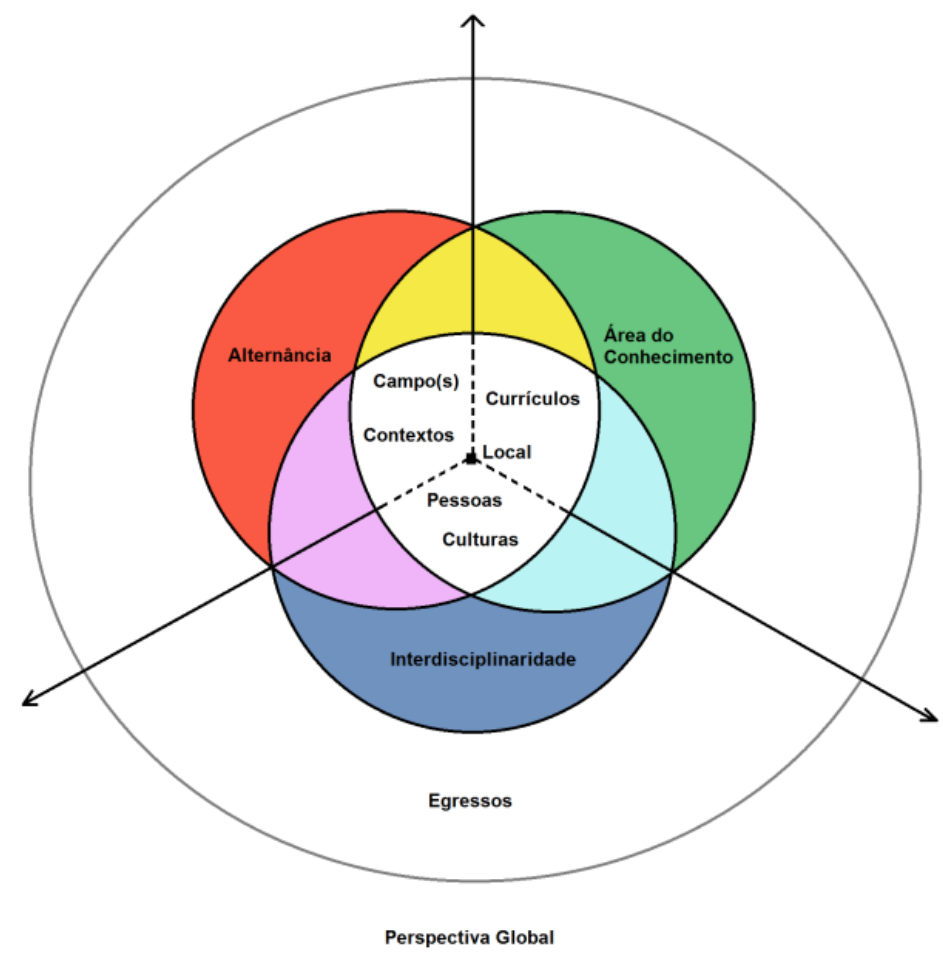

Fonte: Pesquisa dos autores (2019). 
A formação de educadoras e educadores do campo em Ciências da Natureza apresentou três elementos centrais, inter-relacionados, que são a alternância nos espaços-tempos de formação, a interdisciplinaridade e a formação por área do conhecimento. $\mathrm{Na}$ intersecção entre os três elementos, figuram os componentes que sustentam a base de tal formação, representados pelos seguintes conceitos: campo(s), contextos, culturas, currículos e pessoas. No movimento que vai do local ao global, representado pelas setas, que juntas formam o espaço tridimensional do mundo vivido, partimos do local em que interagem as pessoas, diferentes populações do campo e suas culturas, nos diferentes contextos, campos, com os quais o currículo dialoga no processo de formação docente do/no campo. No círculo externo aparecem os egressos das LEDOC, que por meio da formação continuada, da pósgraduação e da extensão universitária mantêm o diálogo com a academia.

\section{Ciência - Tecnologia - Sociedade e implicações socioambientais}

O Movimento CTS discute as interações entre Ciência-TecnologiaSociedade e refere-se a um movimento social mais amplo, formado por pacifistas, ambientalistas, cientistas e outros atores sociais, iniciado na década de 1960, com duas correntes no hemisfério norte e uma latino-americana (PLACTS), que objetivam a democratização de temas que envolvem CT. Ambas as correntes problematizam o modelo linear/tradicional de progresso (DC $\rightarrow$ DT $\rightarrow$ DE $\rightarrow$ DS), segundo Auler (2018, p. 53), no qual “o desenvolvimento Científico (DC) gera desenvolvimento Tecnológico (DT), esse gerando o desenvolvimento econômico (DE) que determina, por sua vez, o Desenvolvimento Social (DS)".

Segundo o modelo linear/tradicional de progresso, mais Ciência e Tecnologia (CT) vai produzir, linearmente, mais bemestar social. Com base na análise dos artigos desta pesquisa emergiram questões relacionadas a agrotóxicos, segurança alimentar e Ciência e Tecnologia. A partir da crítica a esse modelo de desenvolvimento da CT, residem os movimentos nesta categoria.

Considerando-se que a CT é supostamente neutra e não sofre influências externas, na discussão sobre os agrotóxicos, mais CT vai produzir agrotóxicos mais potentes, mais eficazes contra as pragas e ervas daninhas e assim aumentar a produtividade e a lucratividade. Com o aumento da produção e exportação 
o país aumenta seu produto interno bruto, gera mais empregos e aumenta sua capacidade de investimentos sociais. Mas, evidentemente, não é isso que acontece na realidade!

$\mathrm{Na}$ vivência real as variáveis são complexas e não permitem análises simplistas e lineares. Os agrotóxicos são produzidos por grandes corporações que detém a propriedade das sementes geneticamente modificadas, das quais o produtor paga royalties e fica refém do pacote tecnológico (semente-fertilizanteagrotóxico), bem como fica submetido às variações do mercado, das bolsas de valores, com impacto direto nos custos de produção.

Segundo ART02-A (Fernandes \& Stuani, 2015, p. 746), “a mídia televisiva e a impressa argumentam que os agrotóxicos são prejudiciais à saúde humana, mas não aborda o problema a fundo", sem problematizar os riscos ao ambiente e à saúde das pessoas. O modelo de produção do agronegócio é insustentável social e ambientalmente, pois os agrotóxicos são compostos de átomos e moléculas que não desaparecem apenas por não estarem em escala macroscópica. Eles interagem com o ar, a água, os alimentos, a fauna, a flora e as células do corpo humano. O Dossiê da Associação Brasileira de Saúde Coletiva (ABRASCO), Carneiro et al. (2015), denuncia os efeitos dos agrotóxicos às pessoas e ao ambiente e critica o modelo agrícola brasileiro, a partir de estudos e pesquisas desenvolvidas em instituições brasileiras reconhecidas.

Segundo ART12-K (Fonseca, Duso \& Hoffmann, 2017, p. 889), os agrotóxicos prejudicam a polinização de outras culturas alimentícias, causando mortandade de abelhas. No Rio Grande do Sul, desde 2018 o Ministério Público Estadual e a Secretaria da Agricultura, Pecuária e Irrigação investigam denúncias de agricultores sobre a queda de produção de uvas e oliveiras em função da deriva na aplicação do herbicida 2,4-D na fase préplantio de soja. A deriva corresponde à parcela do agrotóxico pulverizado que, por ação, principalmente, do vento, atinge outras culturas.

Conforme Marchi (2018), que investigou esta situação, das 50 amostras, 30 laudos já foram analisados e 29 confirmaram a presença do princípio ativo do 2,4-D nas videiras, oliveiras e plantas nativas, o que afetou o desenvolvimento das plantas. $\mathrm{O}$ número de denúncias pode ser ainda maior. Tal herbicida é conhecido na história mundial por fazer parte da fórmula do denominado "agente laranja", utilizado pelos norte-americanos na guerra do Vietnã. 
Para ART12-A (Fonseca, Duso \& Hoffmann, 2017, p. 881), “o uso dos agrotóxicos, além de comprometer a saúde daqueles que trabalham no campo e dos que se alimentam do que é produzido no campo, traz consigo uma concepção de saúde, que além de adoentar e individualizar, afeta nossa diversidade biológica". Nesse contexto, ART12-H (Fonseca, Duso \& Hoffmann, 2017, p. 888) entendem a alimentação como direito básico das pessoas e que “... ela seja adequada às condições culturais, sociais, econômicas, climáticas e ecológicas de cada pessoa, etnia, cultura ou grupo social".

Por conta da velocidade com a qual os acontecimentos se sucedem na pequena janela do tempo de nossa vida é legítima a preocupação com o que compõe nossa alimentação, nossa fonte de energia, por conseguinte com a nossa saúde. Daí a emergência do debate sobre a segurança alimentar e nutricional. Enquanto somos expostos à contaminação por agrotóxicos o desenvolvimento econômico fica restrito às grandes corporações e o desenvolvimento social, insiste em não chegar. Logo, o desenvolvimento científico-tecnológico não é nem neutro, tampouco linear e que o modelo linear/tradicional de progresso só se sustenta, segundo Auler (2002, p. 78), a partir da concepção de neutralidade da CT.
Portanto, à Educação do Campo cabe problematizar as contradições vividas no campo que envolvem, também, a questão dos agrotóxicos e suas relações com as pessoas e o ambiente, a partir da concepção de não neutralidade da Ciência e Tecnologia, ou seja, reconhecendo que a CT está sujeita à influência de fatores externos. Para ART12-R (Fonseca, Duso \& Hoffmann, 2017, p. 893) "ao abordar a temática agrotóxicos à luz de questões sociais, vêm à tona outros aspectos de cunho econômico, político, cultural e de projeto de sociedade" que coletivamente queremos construir. Auler (2018, p. 129), em uma obra com características do PLACTS, problematiza no âmbito do capitalismo globalizado o equívoco de seguir o caminho trilhado pelos países desenvolvidos, pois é social e ambientalmente insustentável para o planeta. O referido autor sinaliza no contexto da Educação do Campo a opção pela agroecologia em oposição ao consumo de agrotóxicos, como elemento do caminho a ser trilhado na construção de uma sociedade mais saudável, justa e igualitária.

\section{Considerações finais}

A Educação do Campo e as Ciências da Natureza foram protagonistas de um amoroso encontro organizado por uma 
política governamental que vem sendo esvaziada nos últimos anos, pelos cortes no financiamento, relatados por ART09-N (Prsybyciem, Santos \& Sartori, 2017, p. 959), que inviabilizam condições mínimas de funcionamento de boa parte dos cursos.

As conjunturas política e econômica não apresentam perspectivas de melhoria no curto prazo, em função do modelo de desenvolvimento em curso, de perseguir o crescimento da economia, sem considerar as perdas sociais e ambientais advindas de tal escolha, bem como das práticas neoliberais privatistas de encolhimento da estrutura do Estado. Não sabemos o preço a ser pago por tais escolhas, mas decerto que implicará na produção científica neste campo do conhecimento. Tal aspecto vem a confirmar o caráter de não neutralidade da educação e da CT.

A Educação do Campo, segundo ART12-B (Fonseca, Duso \& Hoffmann, 2017, p. 884), enquanto projeto de educação específica, "historicamente localizada e legitimada nas demandas dos movimentos sociais e povos tradicionais, não deve ser compreendida como um espaço de mera aplicação dos conhecimentos sistematizados da já consolidada área do Ensino de Ciências". Pelo contrário, as contradições vividas são objeto de problematização e as Ciências da Natureza atuam no sentido de contribuir para a compreensão da realidade do campo. Realidade esta, complexa e não abarcável por um único campo disciplinar, requerendo assim uma abordagem interdisciplinar. Nesse contexto, surge o desafio de aprofundar aspectos conceituais e epistemológicos da interdisciplinaridade na Educação do Campo, em função da ausência destes aspectos na literatura analisada.

Por fim, sintetizamos com a contribuição desta pesquisa para a construção dos aspectos teóricometodológicos da Articulação FreirePLACTS, no contexto da Educação do Campo, com a presença de três elementos que balizaram a articulação desta tríade, que são: os seres humanos, os contextos e as intencionalidades. Tais elementos são indissociáveis entre si, pois figuram com centralidade nos metatextos resultantes das três categorias finais que emergiram desta pesquisa.

Logo, nesse percorrer da literatura socializada nos periódicos, identificamos que as articulações das Licenciaturas em Educação do Campo com a área das Ciências da Natureza, se relacionam principalmente à formação docente na referida área do conhecimento, mas sem isolar a formação do currículo, nem dissociar a questão ambiental da social e da educacional. 
Desse modo, sintetizamos a contribuição desta pesquisa a partir dos três elementos que unem a tríade do referencial teórico. Nestes, os seres humanos, educadores, educadoras e estudantes, que vivem e trabalham nos diferentes contextos de campo, que vivenciam e problematizam as intencionalidades na Educação, nas Ciências da Natureza e na sociedade, encontram na Educação do Campo um lugar de debate sobre as contradições vividas e de construção de outros caminhos possíveis em termos de sociedade.

\section{Referências}

Alves-Mazzotti, A. J., \& Gewandznajder, F. (1998). O método nas ciências naturais $e$ sociais: pesquisa quantitativa $e$ qualitativa. São Paulo, SP: Pioneira.

Araújo, J. P., Assis, M. P., \& Costa, E. R. (2017). A sustentabilidade, a educação ambiental e o curso de Educação do Campo: é possível essa aproximação? Revista Brasileira de Educação do Campo, 2(3), 921-940. https://doi.org/10.20873/uft.25254863.2017v2n3p921

Arroyo, M. G., Caldart, R. S., \& Molina, M. C. (2004). Por uma educação do campo. Petrópolis, RJ: Vozes.

Auler, D. (2002). Interações entre CiênciaTecnologia-Sociedade no Contexto da Formação de Professores de Ciências (Tese de Doutorado). Universidade Federal de Santa Catarina, Florianópolis.
Auler, D. (2018). Cuidado! Um cavalo viciado tende a voltar para o mesmo lugar. Curitiba, PR: Appris.

Borges, M. G., Faria, J. E. S., \& Brick, E. M. (2017). Fenômenos como mediadores do processo educativo em Ciências da Natureza e Matemática na Educação do Campo. Revista Brasileira de Educação do Campo, 2(3), 965-990. https://doi.org/10.20873/uft.2525$\underline{4863.2017 \mathrm{v} 2 \mathrm{n} 3 \mathrm{p} 965}$

Brito, R. S., \& Silva, T. G. R. (2015). Educação do Campo: formação em ciências da natureza e o estudo da realidade. Educação \& Realidade, 40(3), 763-784. http://dx.doi.org/10.1590/2175$\underline{623645797}$

Carneiro, F. F., Augusto, L. G. S., Rigotto, R. M., Friedrich, K., \& Búrigo, A. C. (Org.). (2015). In Dossiê ABRASCO: um alerta sobre os impactos dos agrotóxicos na saúde. Rio de Janeiro, RJ: EPSJV; São Paulo, SP: Expressão Popular.

Coordenação de Aperfeiçoamento de Pessoal de Nível Superior - CAPES. Plataforma Sucupira. Brasília. Recuperado de:

https://sucupira.capes.gov.br/sucupira/publ ic/consultas/coleta/veiculoPublicacaoQuali s/listaConsultaGeralPeriodicos.jsf

Crepaldi, M. M., Klepka, V., \& Pinto, T. H. O. (2017). Interculturalidade e conhecimento tradicional sobre a Lua na formação de professores no/do campo. Revista Brasileira de Educação do Campo, 2(3), https://doi.org/10.20873/uft.2525$\underline{4863.2017 \mathrm{v} 2 \mathrm{n} 3 \mathrm{p} 836}$

Cunha, M. B. M., \& Silva, J. L. P. B. (2016). Complexos temáticos na formação de professores do campo. Educar em Revista, 32(61), 171-188. http://dx.doi.org/10.1590/0104-4060.45967 
Dagnino, R. (Org.). (2010). Estudos sociais da ciência e tecnologia e política de ciência e tecnologia: abordagens alternativas para uma nova América Latina. Campina Grande, PB: EDUEPB.

Decreto $\mathrm{N}^{\mathrm{o}} 7.352$, de 04 de novembro de 2010. (2010, 04 de novembro). Dispõe sobre a política de educação do campo e o Programa Nacional de Educação na Reforma Agrária - PRONERA. MEC/SECADI: Brasília. Recuperado de: http://www.planalto.gov.br/ccivil_03/_ato2 $\underline{\text { 007-2010/2010/decreto/d7352.htm }}$

Delizoicov, D., Angotti, J. A. P., \& Pernambuco, M. M. C. A. (2002). Ensino de Ciências: fundamentos e métodos. São Paulo, SP: Cortez.

Edital de Seleção $n^{0} 02$ SESU/SETEC/SECADI/MEC, de 31 de agosto de 2012. (2012, 31 de agosto). PROCAMPO. Brasília. Recuperado de: http://pronacampo.mec.gov.br/images/pdf/ edital \%2002 31082012.pdf

Faleiro, W., \& Farias, M. N. (2016). Formadores de professores em Educação do Campo em Goiás. Revista Brasileira de Educação do Campo, 1(1), 88-106. https://doi.org/10.20873/uft.2525$\underline{4863.2016 \mathrm{v} 1 \mathrm{n} 1 \mathrm{p} 88}$

Fernandes, B. M., Cerioli, P. R., \& Caldart, R. S. (2004). "Primeira Conferência Nacional 'Por uma educação básica do campo': texto preparatório”. In Arroyo, M. G., Caldart, R. S., \& Molina, M. C. (Orgs.). Por uma educação do campo (pp. 15-30). Petrópolis, RJ: Vozes.

Fernandes, C. S., \& Stuani, G. M. (2015). Agrotóxicos no Ensino de Ciências: uma pesquisa na educação do campo. Educação \& Realidade, 40(3), 745-762. https://dx.doi.org/10.1590/2175$\underline{623645796}$
Fonseca, E. M., Duso, L. \& Hoffmann, M. B. (2017). Discutindo a temática agrotóxicos: uma abordagem por meio das controvérsias sociocientíficas. Revista Brasileira de Educação do Campo, 2(3), 881-898.

https://doi.org/10.20873/uft.2525-

$\underline{4863.2017 \mathrm{v} 2 \mathrm{n} 3 \mathrm{p} 881}$

Formigosa, M. M., Marchi, M. I., Del Pino, J. C., \& Quartieri, M. T. (2017). Júri simulado e tempestade cerebral: entendendo a implantação da Usina Hidrelétrica de Belo Monte. Revista Brasileira de Educação do Campo, 2(3), 899-920.

https://doi.org/10.20873/uft.2525-

$\underline{4863.2017 \mathrm{v} 2 \mathrm{n} 3 \mathrm{p} 899}$

Freire, P. (2019). Pedagogia do Oprimido. Rio de Janeiro, RJ: Paz e Terra.

Freire, P. (1992). Pedagogia da Esperança: um reencontro com a Pedagogia do Oprimido. Rio de Janeiro, RJ: Paz e Terra.

Freire, P. (1995). À sombra desta mangueira. São Paulo, SP: Olho d'água.

Freire, P. (2006). Extensão ou Comunicação. Rio de Janeiro, RJ: Paz e Terra.

Gonsalves, E. P. (2001). Conversas sobre iniciação à pesquisa científica. Campinas, SP: Alínea.

Halmenschlager, K. R., Camillo, J., Fernandes, C. S., Del Mônaco, G., \& Brick, E. M. (2017). Articulações entre Educação do Campo e Ensino de Ciências e Matemática Presentes na Literatura: Um Panorama Inicial. Ensaio Pesquisa em Educação em Ciências, 19(e2800), 01-21. http://dx.doi.org/10.1590/1983$\underline{21172017190131}$ 
Japiassu, H. (1976). Interdisciplinaridade e Patologia do saber. Rio de Janeiro, RJ: Imago,

Marchi, C. (2018). Após grande número de denúncias, Seapi ganha mais prazo para relatório sobre herbicida. Porto Alegre, RS: Correio do Povo. 4125(2018). Recuperado de: https://www.correiodopovo.com.br/Noticia s/Rural/2018/12/668039/Apos-grandenumero-de-denuncias,-Seapi-ganha-maisprazo-para-relatorio-sobre-herbicida

Marques, L. O. C. (2017). Interculturalidade na formação de professores do campo: análise de uma experiência. Revista Brasileira de Educação do Campo, 2(2), 447-471. https://doi.org/10.20873/uft.2525-

4863.2017v2n2p447

Mendes, M. P. L., \& Grilo, J. S. P. A. (2017). Contribuição da História das Ciências para formação de educadores do campo. Revista Brasileira de Educação do Campo, 2(2), 632-649. https://doi.org/10.20873/uft.2525$\underline{4863.2017 \mathrm{v} 2 \mathrm{n} 2 \mathrm{p} 632}$

Minayo, M. C. S. (Org.). (2002). Pesquisa Social: teoria, método e criatividade. Petrópolis, RJ: Vozes.

Molina, M. C. (Org.). (2014). Licenciaturas em Educação do Campo e o ensino de Ciências Naturais: desafios à promoção do trabalho docente interdisciplinar. Brasília, DF: MDA.

Molina, M. C. (2015). Expansão das licenciaturas em Educação do Campo: desafios e potencialidades. Revista Educar em Pesquisa, 31(55), 145-166. http://dx.doi.org/10.1590/0104-4060.39849

Molina, M. C. (2017a). Contribuições das Licenciaturas em Educação do Campo para as políticas de formação de educadores. Educação \& Sociedade, 38(140), 587-609. http://dx.doi.org/10.1590/es0101$\underline{73302017181170}$

Molina, M. C. (Org.). (2017b). Licenciaturas em Educação do Campo e o ensino de Ciências Naturais: desafios à promoção do trabalho docente interdisciplinar. Volume II. Brasília, DF: Editora UNB.

Moradillo, E. F., Messeder Neto, H. S., \& Massena, E. P. (2017). Ciências da Natureza na Educação do Campo: em defesa de uma abordagem sócio-histórica. Revista Brasileira de Educação do Campo, 2(3), 991-1019. https://doi.org/10.20873/uft.2525$\underline{4863.2017 \mathrm{v} 2 \mathrm{n} 3 \mathrm{p} 991}$

Moraes, R., \& Galiazzi, M. C. (2016). Análise Textual Discursiva. Ijuí, RS: Unijuí.

Moreira, A. F. B., \& Silva, T. T. (2005). (Org.). Currículo, Cultura e Sociedade. São Paulo, SP: Cortez.

Portaria $\mathrm{n}^{\mathrm{o}}$ 072, de 21 de dezembro de 2012. (2012, 21 de dezembro). Resultado Final do processo de seleção regido pelo Edital SESU/SETEC/SECADI $n^{\circ} 2$, de 31 de agosto de 2012. MEC/SECADI: Brasília. Recuperado de: http://portal.mec.gov.br/index.php?option= com_docman\&view $=$ download\&alias $=132$ 99-potaria-72-21-dezembro-2012pronacampo-pdf\&category_slug=junho$\underline{\text { 2013-pdf \&Itemid }=30192}$

Universidade Federal do Rio Grande do Sul - UFRGS. (2013). Projeto Pedagógico do Curso de Graduação Licenciatura Em Educação do Campo. Porto Alegre. Recuperado de: https://www.ufrgs.br/liceducampofaced/pr ojeto-pedagogico/

Prsybyciem, M. M., Santos, A. P., \& Sartori, J. (2017). Formação de professores em Ciências da Natureza para escolas 
do/no campo na UFFS - Campus Erechim: perspectivas e desafios. Revista Brasileira de Educação do Campo, 2(3), 941-964. https://doi.org/10.20873/uft.25254863.2017v2n3p941

Sacristán, J. G. (2013). O que significa o currículo? In Sacristán, J. G. (Org.). Saberes e incertezas sobre o currículo (pp. 16-35). São Paulo, SP: Penso.

Snyders, G. (1988). A Alegria na Escola. São Paulo, SP: Manole.

\section{Informações do artigo / Article Information}

Recebido em : 28/01/2019

Aprovado em: 08/07/2019

Publicado em: 19/01/2020

Received on January 28th, 2019

Accepted on July 08th, 2019

Published on January, 19th, 2020

Contribuições no artigo: Os autores foram os responsáveis por todas as etapas e resultados da pesquisa, a saber: elaboração, análise e interpretação dos dados; escrita e revisão do conteúdo do manuscrito e; aprovação da versão final publicada.

Author Contributions: The author were responsible for the designing, delineating, analyzing and interpreting the data, production of the manuscript, critical revision of the content and approval of the final version published.

Conflitos de interesse: Os autores declararam não haver nenhum conflito de interesse referente a este artigo.

Conflict of Interest: None reported.

Orcid

Antonio Marcos Teixeira Dalmolin

http://orcid.org/0000-0002-9634-622X

Rosane Nunes Garcia

(iD) http://orcid.org/0000-0002-4647-6245

\section{Como citar este artigo / How to cite this article}

APA

Dalmolin, A. M. T., \& Garcia, R. N. (2020). Licenciaturas em Educação do Campo da área de Ciências da Natureza: análise da produção em periódicos nacionais. Rev. Bras. Educ. Camp., 5, e6455. http://dx.doi.org/10.20873/uft.rbec.e6455

ABNT

DALMOLIN, A. M. T.; GARCIA, R. N. Licenciaturas em Educação do Campo da área de Ciências da Natureza: análise da produção em periódicos nacionais. Rev. Bras. Educ. Camp., Tocantinópolis, v. 5, e6455, 2020. http://dx.doi.org/10.20873/uft.rbec.e6455 